\title{
Evaluation of a serum 17-hydroxyprogesterone as predictor of semen parameter(s) improvement in men undergoing medical treatment for infertility
}

Thiago Fernandes Negris Lima; Evgeniya Rakitina; Ruben Blachman-Braun; Ranjith Ramasamy Department of Urology, University of Miami Miller School of Medicine, Miami, FL, United States

Cite as: Lima TFN, Rakitina E, Blachman-Braun R, et al. Evaluation of a serum 17hydroxyprogesterone as predictor of semen parameter(s) improvement in men undergoing medical treatment for infertility. Can Urol Assoc J 2020 December 15; Epub ahead of print. http://dx.doi.org/10.5489/cuaj.6846

Published online December 15, 2020

$* * *$

\section{Abstract}

Introduction: The goal of medical therapy for infertile men with testosterone deficiency (TD) is to improve intratesticular testosterone (ITT). There is a gap in knowledge to identify those who will respond with semen parameter(s) improvement. We hypothesized that serum 17hydroxyprogesterone (17-OHP) - a marker of ITT - can be used to predict improvement of semen parameter(s).

Methods: Between July 2018 and January 2020, we conducted a prospective study of 31 men with primary infertility, TD, and secondary hypogonadism receiving clomiphene citrate (CC) and/or human chorionic gonadotropin (hCG) for three months. We assessed baseline and followup hormones, including testosterone, 17-OHP, semen parameter(s), and demographics. Semen quality upgrading was based on assisted reproduction eligibility: in-vitro fertilization $(<5$ million), intrauterine insemination (IUI) (5-9 million), and natural pregnancy ( $>9$ million). Variables were compared using the Mann-Whitney U or Wilcoxon rank test. Results: Twenty-one men received CC and 10 received CC/hCG. Median followup was 3.7 (3.3-5.1) months. Sixteen men upgraded semen quality. Six of 10 men with baseline total motile sperm count (TMSC) of 0 had motile sperm after treatment, and 11/20 men with TMSC $<5$ upgraded semen quality into TMSC $>5$ range. Low 17-OHP was the only factor that predicted semen quality upgrading. Men with $17-\mathrm{OHP} \leq 55 \mathrm{ng} / \mathrm{dL}$ upgraded semen quality and improved hormones, whereas men with 17-OHP $>55 \mathrm{ng} / \mathrm{dL}$ did not upgrade semen quality.

Conclusions: Medical therapy for infertile men with TD resulted in the improvement of sperm concentration, TMSC, testosterone, and 17-OHP. Semen quality upgrading appears to be more 
significant in patients with low 17-OHP, suggesting that ITT can be used as a biomarker to predict semen parameter(s) improvement.

\section{Introduction}

According to the U. S. Department of Health and Human Services, for every 100 couples in the United States, 12 to 13 have trouble conceiving a child. ${ }^{1}$ Although many times the cause of infertility is a combination of both male and female factors, male infertility still accounts for over one-third of such cases. Medical therapy for male factor infertility remains largely empiric ${ }^{2}$ and relies on off-label use of oral medications known to increase intratesticular testosterone (ITT) levels, for example selective estrogen receptor modulators such as clomiphene citrate (CC) and gonadotropins such as human chorionic gonadotropin (hCG). ${ }^{3}$

Spermatogenesis is controlled by Sertoli cells and responds to multiple paracrine factors and steroidogenic factors secreted from Leydig cells. ${ }^{4}$ Roth et al. ${ }^{5}$ showed with their mouse models that ITT level is positively correlated with the extent of spermatogenesis and the latter ceases when ITT falls below $75 \%$ of baseline. Coviello et al. ${ }^{6}$ also showed that males receiving a contraceptive regimen of testosterone enanthate and levonorgestrel presented with markedly suppression of gonadotropins and dramatic suppression of ITT (reduction of 98\%), associated with severe sperm parameter[s] decline, since almost all patients became azoospermic. Additionally, fertile males receiving exogenous testosterone combined with hCG 500 IU every other day had no impact on semen parameter[s] in a long-term follow up (up to 1 year), showing that direct stimulation of Leydig cells to produce ITT was able to maintain spermatogenesis ${ }^{7}$. These results support Zirkin et al. ${ }^{8}$ findings of ITT (in higher levels than serum testosterone) to be necessary for spermatogenesis. In this study, reductions of up to $80 \%$ of ITT were related to a quantitative decrease in sperm concentration, whereas further decrease of ITT resulted in inability to maintain complete spermatogenesis. A number of studies have been performed, trying to investigate the relationship between ITT and male infertility ${ }^{9}$. Until now, ITT has been measured through testicular aspirations and surgical biopsies, which inherently harbor the risk of damage to the testicles and cause potential complications such as infection, bleeding, and infertility ${ }^{10}$. Amory et al. ${ }^{11}$ showed a positive correlation between serum levels of 17-OHP and ITT concentrations in response to $\mathrm{hCG}$ administration as confirmed by testicular aspiration analysis. In a recent study, we evaluated serum 17-OHP as a biomarker for ITT in hypogonadal men who were treated with medications that alter ITT $^{12}$. We also demonstrated that it can be used to monitor response in men with hypogonadotropic hypogonadism ${ }^{13}$.

Our current study focuses on the response of infertile men with testosterone deficiency to targeted therapy with CC and CC combined with hCG. The current gap in knowledge is determining predictors of semen parameter[s] improvement following medical therapy using $\mathrm{CC}^{14}$ and hCG. We hypothesized that men with lower baseline 17-OHP will experience a more 
significant improvement in semen parameter[s] (semen quality upgrading) after medical therapy, based on the correlation between restoration of adequate levels of 17-OHP (ITT) and quantitative spermatogenesis $^{8,15}$. Our objective was to evaluate serum 17-OHP's reliability as a serum biomarker of ITT, it's response to hormonal therapy and identify ideal candidates for medical therapy in infertile men as a step toward personalized medicine.

\section{Methods}

We prospectively followed men who complained of primary infertility, had abnormal semen parameter[s] according to the World Health Organization (WHO) $5^{\text {th }}$ edition criteria ${ }^{16}$ on at least 2 properly collected semen analyses, and had testosterone deficiency (Total testosterone < 300ng/dL drawn on separate occasions before 10AM) between July 2018 to January 2020 under an Institutional Review Board approved protocol. We compared pre- and post-treatment values of T, 17-OHP, follicle-stimulating hormone (FSH), luteinizing hormone (LH), and semen parameter[s] in men who received agents that increase ITT levels (CC and CC $+\mathrm{hCG}$ ). Men with idiopathic infertility or secondary hypogonadism received CC (25mg orally every other day) if TT was $<300 \mathrm{ng} / \mathrm{dL}$ (on 2 separate occasions) and LH was between 2-8 IU/mL. Patients with a history of testosterone abuse and interested in spermatogenesis recovery were prescribed oral $\mathrm{CC}$ $50 \mathrm{mg}+$ hCG 2000 IU subcutaneously every other day if baseline semen analysis and hormone levels were not in normal range. We included men with a history of testosterone abuse and azoospermia interested in spermatogenesis recovery, men with azoospermia or TMSC $<9$ associated with idiopathic infertility and men with secondary hypogonadism with TMSC $<9$. We excluded men with idiopathic hypogonadotropic hypogonadism, men who had varicocele repair during the period of follow-up, patients who were on TRT, hCG or CC therapies during the baseline assessment, azoospermia due to Klinefelter syndrome or Y-chromosome microdeletion, those who were lost to follow-up, or those who changed therapy before follow-up evaluation to guarantee homogeneity of patients. Also, these patients were excluded because these groups of men require specific regimens of medication to improve ITT production. All men underwent full clinical evaluation, including evaluation of semen parameter[s] (performed at the same laboratory by the same technician according to the WHO $5^{\text {th }}$ edition criteria ${ }^{16}$ ), and serum 17-OHP and $\mathrm{T}$ which were drawn at the same lab from 6:00 am - 10:00 am. All semen samples were collected with an abstinence period of 2-7 days. Patients using medications that altered ITT, which included exogenous testosterone, CC or hCG; stopped treatment for 8 weeks prior to baseline evaluation. The patients were evaluated at baseline and 3 months after beginning therapy.

We classified men with baseline total motile sperm count (TMSC) in 3 groups: TMSC < 5, TMSC 5-9 and TMSC $>9$ according to Samplaski et al ${ }^{17}$. The TMSC groups were created based on the eligibility of ART and are useful to guide couples on success rates of ART procedures. Males with TMSC $<5$ usually are recommended to proceed with IVF because of the reduced amount of motile sperm. Males with TMSC 5-9 are candidates for IUI, but also IVF. 
Males with TMSC $>9$ are eligible for all types of ART and natural conception. TMSC was calculated using the formula: ejaculate volume $(\mathrm{mL}) \mathrm{X}$ concentration (million $/ \mathrm{mL}) \mathrm{X}$ motile fraction. Semen quality upgrade was defined by the improvement of the TMSC group after treatment or by patients with TMSC of 0 having motile sperm in the ejaculate during follow-up.

In order to develop a "standard" level for serum 17-OHP, we performed a cross-sectional analysis of a representative sample of 247 fertile controls (men who were evaluated for vasectomy reversal, erectile dysfunction, Peyronie's disease, orchialgia, and vasectomy evaluation) aged $39.5 \pm 11.93$ years. The $5^{\text {th }}, 25^{\text {th }}, 50^{\text {th }}$, and $75^{\text {th }}$ percentile for serum $17-\mathrm{OHP}$ was $34.2,55,72$ and $105.5 \mathrm{ng} / \mathrm{dL}$, respectively. We used $55 \mathrm{ng} / \mathrm{dL}$ as the threshold to determine the lower limit of normal. The lower limit of normal established by commercial laboratories ranges from 27-199 ng/dL (LABCORP - www.labcorp.com) and from 33-195 ng/dL (QUEST www.questdiagnotics.com). This ranges were validated internally in each company and based on studies in the pediatric population ${ }^{18,19,20}$. We preferred to use the cut-point of $55 \mathrm{ng} / \mathrm{dL}$ because we wanted provide the best threshold that demonstrated improvement in semen parameters. Therefore, we evaluated men based on serum 17-OHP $\leq 55 \mathrm{ng} / \mathrm{dL}$ (low 17-OHP) or $17-\mathrm{OHP}>55 \mathrm{ng} / \mathrm{dL}$ (normal 17-OHP).

\section{Statistical analysis}

Statistical analysis was performed with SPSS version 24.0 software. Categorical variables were presented as absolute values and frequencies. For continuous variables, means and standard deviations $( \pm \mathrm{SD})$ or medians and interquartile ranges [25-75] were calculated according to the data distribution as indicated by the normality test. A comparison of numerical variables between groups was performed using the Mann-Whitney U or Wilcoxon rank test as required. A p-value $<0.05$ was considered statistically significant. Based on a statistical power calculation using ClinCalc software (https://clincalc.com/stats/samplesize.aspx), and a study published on changes in sperm concentration after CC therapy, ${ }^{14}$ we needed at least 30 men to achieve acceptable statistical power of $80 \%$ and $\alpha=0.05$.

\section{Results}

Between July 2018 to January 2020, a total of 21 men received CC and 10 received the combination of CC and hCG. The clinical and demographic characteristics as well as history of testosterone treatment, indication for treatment, and follow-up time of the analyzed men are evident in Table 1. Comparison between hormonal levels and semen analysis parameter[s] at baseline and during follow-up are illustrated in Table 2. Overall, there was a significant elevation of all hormone levels in addition to sperm concentration and TMSC. At baseline, most men had $17-\mathrm{OHP} \leq 55 \mathrm{ng} / \mathrm{dL}(19 / 31,61.3 \%)$ and TMSC $<5$ (20/31, 64.5\%). Males with previous history of steroid anabolic use had similar baseline levels of 17-OHP and mean testicular volume when compared to those without previous history $(24$ [16 - 88] ng/dL vs. 49 [28.5 - 72] ng/dL, respectively, $\mathrm{p}=0.306$ and 14.7 [10.5-16.5] cc vs. 12 [10.8 - 14] cc, respectively, $\mathrm{p}=0.208$ ). 
A total of 17 out of 23 (73.9\%) men upgraded semen quality after treatment. Of the 17 men, 14 had TMSC $<5$, including 7 men with TMSC of 0 at baseline that presented with motile sperm during follow-up. Also, the 3 patients with baseline TMSC 5-9 improved to TMSC $>9$ range. $8 / 31(25.8 \%)$ men had baseline TMSC $>9$ and therefore could not have semen quality upgrade. In addition, males with oligozoospermia had significant improvement in sperm concentration $(1.7[0.68-6.9]$ to 9.3 [4.9 - 15] million/cc, $p=0.003)$. Of the patients that improved semen quality, $47 \%(8 / 17)$ had previous history of anabolic steroid use. Also, among men who upgraded semen quality, 17-OHP improved in 16/17 patients, with a median improvement of 56 [28-102] ng/dL.

We then evaluated the infertile men according to baseline serum 17-OHP levels, and found that men with low 17-OHP had a significant improvement in sperm concentration and TMSC (1 [0 - 10] to 9.2 [0.7 - 19] million/cc, $p=0.002$, and 0.3 [0 - 9.6] to 10.2 [0.1 - 23] million, $\mathrm{p}=0.014$, respectively). On the other hand, men with normal 17-OHP did not have a significant change in sperm concentration and TMSC $(p>0.05)$. Besides that, only 1 out of 3 (33.3\%) men with TMSC of 0 and normal 17-OHP improved SA during the follow-up.

Conversely, 5 out of 7 (71.4\%) men with TMSC of 0 and low 17-OHP had motile sperm during the follow-up. Also, men with low 17-OHP had a significant increase in 17-OHP and T, as opposed to men with normal 17-OHP who only experienced significant amelioration in serum $\mathrm{T}$ levels. (Table 3 and Figure).

\section{Discussion}

The management of idiopathic infertility in patients with low testosterone is challenging. Since testosterone replacement therapy for low testosterone has the potential to inhibit spermatogenesis ${ }^{21}$, studies have described the use of off-label drugs for the treatment of these men. ${ }^{13,14,22-25}$ Based on the hypothesis that spermatogenesis disruption is caused by low levels of intratesticular testosterone, ${ }^{5,16,26}$ we analyzed the outcomes of men treated with off-label medications that knowingly increase ITT, comparing baseline and follow-up semen parameter[s] to serum levels of 17-OHP (ITT serum biomarker) and T. We discovered that men with low 17OHP are better responders to medical treatment and, therefore, they are likely the best candidates for medical therapy.

Men with non-obstructive azoospermia have always been a challenge to medical therapy. Hussein et al. suggested that after clomiphene citrate therapy, $64.3 \%$ of patients demonstrated sperm in their semen analyses ranging from 1 to 16 million sperm $/ \mathrm{mL}$, with a mean sperm density of $3.8 \mathrm{million} / \mathrm{mL} .^{27}$ These findings concur with our results, where 5 out of $9(55.5 \%)$ men with azoospermia presented with sperm in the ejaculate after treatment, ranging from 0.2 to $21 \mathrm{million} / \mathrm{cc}$. There is also data suggesting that CC therapy could ameliorate sperm retrieval rates in patients with non-obstructive azoospermia (NOA). Hussein et al. showed that for the 442 patients who remained azoospermic after treatment, successful sperm retrieval was significantly higher (57\%) compared with the control group $(33.6 \%){ }^{28}$ 


\section{7-OHP as a predictor of semen parameter improvement in infertile men}

Clomiphene citrate has an important role in the management of oligozoospermic patients. Our study showed the significant response of these men to medical treatment ( $\mathrm{CC}$ or $\mathrm{CC} / \mathrm{hCG}$ ). This agrees with a recent retrospective analysis of 77 men receiving $\mathrm{CC}$, where 44 (57.14\%) oligozoospermic men had a significant improvement of sperm concentration after approximately 3 months. ${ }^{14}$

Exogenous testosterone use is known to suppress spermatogenesis due to a negative feedback to the hypothalamic-pituitary-gonadal axis and although most men will recover spermatogenesis after cessation, it can take until 2 years ${ }^{21}$. In our study, all men with history of anabolic steroid use had sperm after 105 [98-112] days of follow-up. These findings proved to be better than previously reported by Patel et al. ${ }^{16}$, with spontaneous recovery rate of $64 \%$ to $84 \%$ after 110 days. Although data about medical therapy is poor, this incongruence can be explained by the use of restorative therapies for recovery of spermatogenesis, which could accelerate the rate of recovery ${ }^{29}$.

Our study has several strengths, but it also has its limitations. The strengths include the novelty of the study's findings, especially defining 17-OHP as a baseline predictor of medical therapy response as well as analyzing $17-\mathrm{OHP}$ changes after hCG/CC and correlating to SA parameter[s]. To our knowledge, there are no studies using the concept of semen upgrading for medical therapy in infertile men with idiopathic or secondary infertility. All hormonal level measurements were performed in a single laboratory ${ }^{30}$, between 6:00 am - 10:00 am, and all SA were evaluated in our laboratory facilities by a single technician to reduce the heterogeneity of results. Also, all semen samples from azoospermic patients were centrifuged to exclude cryptozoospermia. However, this is a single institution study with a modest sample size and we based the correlation of 17-OHP with ITT on Amory et al. ${ }^{11}$ findings and our previous study ${ }^{12}$, since repeatedly performing testicular aspiration was not feasible. Furthermore, both 17-OHP and $\mathrm{T}$ are steroid hormones and measurements can vary within samples ${ }^{31,32}$ or with the circadian cycle $^{33}$. Additionally, we did not evaluate pregnancy rates or number of live births as an outcome. We expect that prospective studies in larger populations and longer follow-up that include men with oligospermia and NOA undergoing medical treatment with CC and/or hCG will help better elucidate the role of 17-OHP in the medical management of male infertility. Male infertility conveys a large social, psychological, and economic burden ${ }^{34}$. Thus, identifying biomarkers of medical treatment response in infertile men will be critical for counseling couples, setting expectations, and dictating personalized management. Although the present study provides encouraging results about the potential of 17-OHP as a possible biomarker of medical response, further research needs to be done to confirm our findings and identify the best cut-off value of 17-OHP that provides the highest likelihood of sperm parameter[s] improvement in oligospermic and azoospermic men. 


\section{Conclusions}

Treatment of infertile men with testosterone deficiency using CC and/or hCG resulted in amelioration of sperm concentration and TMSC, concomitantly with serum T and 17-OHP. These improvements appear to be more significant in patients with low 17-OHP. Infertile men with normal 17-OHP seem to benefit less, and prescription of medical therapy should be cautiously evaluated individually. Using serum 17-OHP as a biomarker for ITT and predicting response of semen parameter[s] improvement with medical hormonal therapy could be a step toward personalized medicine. 


\section{7-OHP as a predictor of semen parameter improvement in infertile men}

\section{References}

1. U.S. Department of Health and Human Services. Accessed February 14, 2020. https:/www.hhs.gov/opa/reproductive-health/fact-sheets/female-infertility/index.html

2. Kathrins M, Niederberger C. Diagnosis and treatment of infertility-related male hormonal dysfunction. Nat Rev Urol. 2016;13(6):309-23. doi:10.1038/nrurol.2016.62

3. Carrasquillo R, Chu K, Ramasamy R. Novel Therapy for Male Hypogonadism. Curr Urol Rep. 2018;19(8):63. doi:10.1007/s11934-018-0816-х

4. Niederberger CS, Shubhada S, Kim SJ, et al. Paracrine factors and the regulation of spermatogenesis. World J Urol. 1993;11(2):120-28. doi:10.1007/BF00182039

5. Roth MY, Lin K, Amory JK, et al. Serum LH correlates highly with intratesticular steroid levels in normal men. J Androl. 2010;31(2):138-45. doi:10.2164/jandrol.109.008391

6. Coviello AD, Bremner WJ, Matsumoto AM, et al. Intratesticular testosterone concentrations comparable with serum levels are not sufficient to maintain normal sperm production in men receiving a hormonal contraceptive regimen. $J$ Androl. 2004;25(6):931-938. doi:10.1002/j.1939-4640.2004.tb03164.x

7. Hsieh TC, Pastuszak AW, Hwang K, Lipshultz LI. Concomitant intramuscular human chorionic gonadotropin preserves spermatogenesis in men undergoing testosterone replacement therapy. J Urol. 2013;189(2):647-650. doi:10.1016/j.juro.2012.09.043

8. Zirkin BR, Santulli R, Awoniyi CA, Ewing LL. Maintenance of advanced spermatogenic cells in the adult rat testis: quantitative relationship to testosterone concentration within the testis. Endocrinology. 1989;124(6):3043-3049. doi:10.1210/endo-124-6-3043

9. Shinjo E, Shiraishi K, Matsuyama H. The effect of human chorionic gonadotropin-based hormonal therapy on intratesticular testosterone levels and spermatogonial DNA synthesis in men with non-obstructive azoospermia. Andrology. 2013;1(6):929-35. doi:10.1111/j.2047-2927.2013.00141.x.

10. Jarow JP, Chen H, Rosner TW, et al. Assessment of the androgen environment within the human testis: minimally invasive method to obtain intratesticular fluid. $J$ Androl. 2001;22(4):640-45.

11. Amory JK, Coviello AD, Page ST, et al. Serum 17-hydroxyprogesterone strongly correlates with intratesticular testosterone in gonadotropin-suppressed normal men receiving various dosages of human chorionic gonadotropin. Fertil Steril. 2008;89(2):380-86. doi:10.1016/j.fertnstert.2007.02.059

12. Lima TFN, Patel P, Blachman-Braun R, et al. Serum 17-Hydroxyprogesterone is a Potential Biomarker for Evaluating Intratesticular Testosterone [published online ahead of print, 2020 Mar 13]. J Urol. 2020;101097JU0000000000001016. doi:10.1097/JU.0000000000001016

13. Mouzannar A, Narasimman M, Patel P, et al. Using 17-OHP as Serum Biomarker to Monitor Therapy in Patients With Hypogonadotropic Hypogonadism. Rev Urol. 2019;21(4):180-82.

14. Sharma D, Zillioux J, Khourdaji I, et al. Improvements in semen parameters in men treated with clomiphene citrate-A retrospective analysis. Andrologia. 2019;51(5):e13257. doi:10.1111/and.13257 
15. Robaire B, Zirkin BR. Hypophysectomy and simultaneous testosterone replacement: effects on male rat reproductive tract and epididymal delta 4-5 alpha-reductase and 3 alpha-hydroxysteroid dehydrogenase. Endocrinology. 1981;109(4):1225-233. doi:10.1210/endo-109-4-1225

16. World Health Organization. (2010). WHO laboratory manual for the examination and processing of human semen (5th ed.). Geneva, Switzerland: WHO Press. https://apps.who. int/iris/bitstream/handle/10665/44261/9789241547789_ eng.pdf;jsessionid=CE7B90CB63159541A24E97E20EC 62665? sequence=1

17. Samplaski MK, Lo KC, Grober ED, et al. Varicocelectomy to "upgrade" semen quality to allow couples to use less invasive forms of assisted reproductive technology. Fertil Steril. 2017;108(4):609-12. doi:10.1016/j.fertnstert.2017.07.017

18. Nykänen P, Heinonen K, Riepe FG, Sippell WG, Voutilainen R. Serum concentrations of adrenal steroids and their precursors as a measure of maturity of adrenocortical function in very premature newborns. Horm Res Paediatr. 2010;74(5):358-364. doi:10.1159/000314970

19. Lee MM, Rajagopalan L, Berg GJ, Moshang T Jr. Serum adrenal steroid concentrations in premature infants. J Clin Endocrinol Metab. 1989;69(6):1133-1136. doi:10.1210/jcem69-6-1133.

20. Lashansky G, Saenger P, Fishman K, et al. Normative data for adrenal steroidogenesis in a healthy pediatric population: age- and sex-related changes after adrenocorticotropin stimulation. J Clin Endocrinol Metab. 1991;73(3):674-686. doi:10.1210/jcem-73-3674Patel AS, Leong JY, Ramos L, et al. Testosterone Is a Contraceptive and Should Not Be Used in Men Who Desire Fertility. World J Mens Health. 2019;37(1):45-54. doi:10.5534/wjmh.180036

21. Patel AS, Leong JY, Ramos L, et al. Testosterone Is a Contraceptive and Should Not Be Used in Men Who Desire Fertility. World J Mens Health. 2019;37(1):45-54. doi:10.5534/wjmh.180036

22. Madhusoodanan V, Patel P, Lima TFN, et al. Human Chorionic Gonadotropin monotherapy for the treatment of hypogonadal symptoms in men with total testosterone > 300 ng/dL. Int Braz J Urol. 2019;45(5):1008-012. doi:10.1590/S16775538.IBJU.2019.0132

23. Surbone A, Vaucher L, Primi MP, et al. Clomiphene citrate effect on testosterone level and semen parameters in 18 infertile men with low testosterone level and normal/low gonadotropines level. Eur J Obstet Gynecol Reprod Biol. 2019;238:104-09. doi:10.1016/j.ejogrb.2019.05.011

24. Cannarella R, Condorelli RA, Mongioì LM, et al. Effects of the selective estrogen receptor modulators for the treatment of male infertility: a systematic review and metaanalysis. Expert Opin Pharmacother. 2019;20(12):1517-525. doi:10.1080/14656566.2019.1615057

25. Wheeler KM, Sharma D, Kavoussi PK, et al. Clomiphene Citrate for the Treatment of Hypogonadism. Sex Med Rev. 2019;7(2):272-276. doi:10.1016/j.sxmr.2018.10.001

26. Ramaswamy S, Weinbauer GF. Endocrine control of spermatogenesis: Role of FSH and LH/ testosterone. Spermatogenesis. 2015;4(2):e996025. Published 2015 Jan 26. doi:10.1080/21565562.2014.996025 


\section{7-OHP as a predictor of semen parameter improvement in infertile men}

27. Hussein A, Ozgok Y, Ross L, et al. Clomiphene administration for cases of nonobstructive azoospermia: a multicenter study. J Androl. 2005;26(6):787-793. doi:10.2164/jandrol.04180

28. Hussein A, Ozgok Y, Ross L, et al. Optimization of spermatogenesis-regulating hormones in patients with non-obstructive azoospermia and its impact on sperm retrieval: a multicentre study. BJU Int. 2013;111(3 Pt B):E110-E114. doi:10.1111/j.1464410X.2012.11485.X

29. McBride JA, Coward RM. Recovery of spermatogenesis following testosterone replacement therapy or anabolic-androgenic steroid use. Asian J Androl. 2016;18(3):373380. doi:10.4103/1008-682X.173938

30. Paduch DA, Brannigan RE, Fuchs EF, et al. The laboratory diagnosis of testosterone deficiency. Urology. 2014;83(5):980-988. doi:10.1016/j.urology.2013.12.024

31. Thienpont LM, Van Uytfanghe K, Blincko S, et al. State-of-the-art of serum testosterone measurement by isotope dilution-liquid chromatography-tandem mass spectrometry. Clin Chem. 2008;54(8):1290-1297. doi:10.1373/clinchem.2008.105841

32. Shlykova N, Davidson E, Krakowsky Y, et al. Absent Diurnal Variation in Serum Testosterone in Young Men with Testosterone Deficiency. J Urol. 2020;203(4):817-823. doi:10.1097/JU.0000000000000630

33. Gupta SK, Lindemulder EA, Sathyan G. Modeling of circadian testosterone in healthy men and hypogonadal men. J Clin Pharmacol. 2000;40(7):731-738. doi:10.1177/00912700022009486

34. Mehta A, Nangia AK, Dupree JM, et al. Limitations and barriers in access to care for male factor infertility. Fertil Steril. 2016;105(5):1128-1137.

doi:10.1016/j.fertnstert.2016.03.023 


\section{Figures and Tables}

Fig. 1.

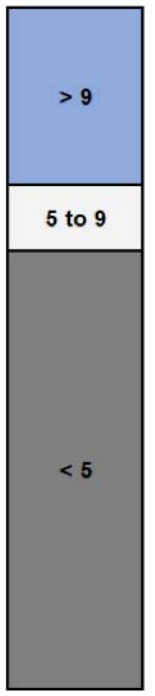

Baseline
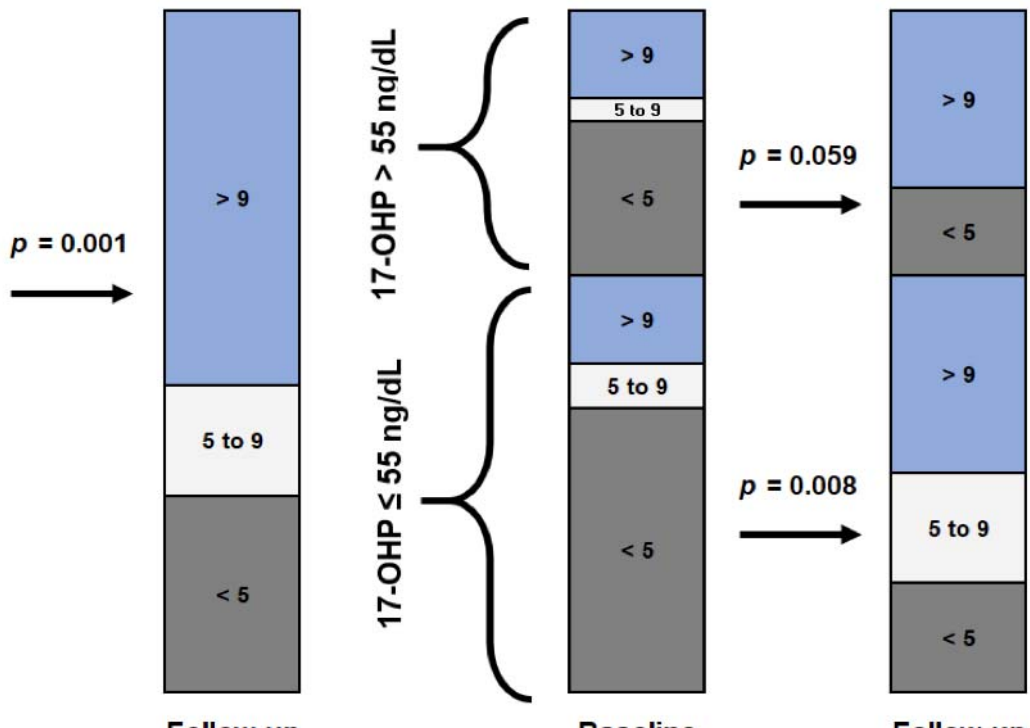

Baseline

Follow-up

\begin{tabular}{|l|c|}
\hline \multicolumn{2}{|l|}{ Table 1. Clinical and demographic characteristics of the analyzed patients } \\
\hline Characteristics & Patients (n=31) \\
\hline Age (years) & $39.6 \pm 6.6$ \\
\hline BMI (kg/m $\left.{ }^{2}\right)$ & $29.9(27.3-33.1)$ \\
\hline Mean testicular volume (cc) & $13.1 \pm 3.1$ \\
\hline Testosterone abuse & $22(71 \%)$ \\
\hline No & $9(29 \%)$ \\
\hline Yes & $28(90.3 \%)$ \\
\hline Indication for treatment & $10(32.2 \%)$ \\
\hline Infertility & $3.7(3.3-4.4)$ \\
\hline Hypogonadism & $3.7(3.3-5.1)$ \\
\hline Time baseline to follow up bloodwork (months) & \\
\hline Time baseline to follow up SA (months) & \\
\hline
\end{tabular}

*In 7 patients, the indication was both infertility and hypogonadism. Mean \pm standard deviation, Median (interquartile range 25-75). BMI: body mass index; SA: semen analysis. 
17-OHP as a predictor of semen parameter improvement in infertile men

\begin{tabular}{|c|c|c|c|}
\hline & Baseline $(n=31)$ & Followup $(n=31)$ & $\mathrm{p}$ \\
\hline \multicolumn{4}{|l|}{ Hormones } \\
\hline 17-OHP, ng/dL & $41(24-72)$ & $88(61-131)$ & $<0.001$ \\
\hline Testosterone, ng/dL & $213(137-367)$ & $415(324-669)$ & $<0.001$ \\
\hline FSH, mIU/mL & $4.4(3.4-15.8)$ & $7(3.4-19.4)$ & 0.024 \\
\hline $\mathrm{LH}, \mathrm{mIU} / \mathrm{mL}$ & $3.7(2.7-5.8)$ & $5.2(1.9-7.7)$ & 0.022 \\
\hline \multicolumn{4}{|l|}{ Semen analysis } \\
\hline Volume & $2.3(1.5-3.3)$ & $2.6(1.8-3.2)$ & 0.368 \\
\hline $\begin{array}{l}\text { Sperm concentration, } \\
\text { million/cc }\end{array}$ & $1(0-10)$ & $9.2(0.7-19)$ & 0.002 \\
\hline Total motility, million & $0.17(0-0.58)$ & $0.45(0.20-0.56)$ & 0.115 \\
\hline TMSC & $0.3(0-9.6)$ & $10.2(0.1-23)$ & 0.014 \\
\hline \multicolumn{4}{|l|}{ TMSC category } \\
\hline$<5$ & $20(64.5 \%)$ & $9(29 \%)$ & \\
\hline $5-9$ & $3(9.7 \%)$ & $5(16.1 \%)$ & \\
\hline$>9$ & $8(25.8 \%)$ & $17(54.8 \%)$ & 0.001 \\
\hline
\end{tabular}

Median (interquartile range 25-75). Wilcoxon rank test was used to analyze the change in variables over time. Bolded values=statistically significant. 17-OHP: 17-hydroxyprogestrone (ng/dL); FSH: follicle-stimulating hormone (mIU/mL); LH: luteinizing hormone $(\mathrm{mIU} / \mathrm{mL})$; SA: semen analysis; TMSC: total motile sperm count (million). 


\begin{tabular}{|c|c|c|c|c|c|c|}
\hline & \multicolumn{3}{|c|}{$17-O H P>55 \mathrm{ng} / \mathrm{dL}$} & \multicolumn{3}{|c|}{$17-\mathrm{OHP} \leq 55 \mathrm{ng} / \mathrm{dL}$} \\
\hline & Baseline $(\mathrm{n}=12)$ & $\begin{array}{c}\begin{array}{c}\text { Followup } \\
(n=12)\end{array} \\
\end{array}$ & $\mathbf{p}$ & $\begin{array}{c}\text { Baseline } \\
(n=19)\end{array}$ & $\begin{array}{c}\text { Followup } \\
(n=19)\end{array}$ & $\mathbf{p}$ \\
\hline \multicolumn{7}{|l|}{$\begin{array}{l}\text { Followup } \\
\text { hormones }\end{array}$} \\
\hline 17-OHP, ng/dL & $82(69-106.8)$ & $\begin{array}{c}102.5(64.5- \\
134)\end{array}$ & 0.209 & $27(19-35)$ & $86(55-125)$ & $<0.001$ \\
\hline $\begin{array}{l}\text { Testosterone, } \\
\mathrm{ng} / \mathrm{dL}\end{array}$ & $\begin{array}{c}359.6(2243- \\
406.3)\end{array}$ & $\begin{array}{c}474.5(374- \\
617.5)\end{array}$ & 0.019 & $\begin{array}{c}165(120- \\
248)\end{array}$ & $\begin{array}{c}350(301- \\
671.7)\end{array}$ & $<0.001$ \\
\hline $\mathrm{FSH}, \mathrm{mIU} / \mathrm{mL}$ & $8.2(3.4-23.7)$ & $13(3.4-22.8)$ & 0.241 & $4.1(3-8.8)$ & $6(2.1-16.5)$ & 0.052 \\
\hline $\mathrm{LH}, \mathrm{mIU} / \mathrm{mL}$ & $5.1(3.2-5.8)$ & $5.5(3.5-7.4)$ & 0.173 & $3(1-6.4)$ & $4.1(1.8-8.6)$ & 0.074 \\
\hline \multicolumn{7}{|l|}{ Followup SA } \\
\hline Volume & $2.8(2-3)$ & $3(2-3.4)$ & 0.678 & $2(1.5-4)$ & $2.6(1.8-3.1)$ & 0.365 \\
\hline $\begin{array}{l}\text { Sperm } \\
\text { concentration, } \\
\text { million/cc }\end{array}$ & $2.9(0.2-10.1)$ & $8.5(1.8-15)$ & 0.169 & $0.7(0-10)$ & $9.3(0.7-20)$ & 0.004 \\
\hline $\begin{array}{l}\text { Total motility, } \\
\text { million }\end{array}$ & $0.31(0.10-0.57)$ & $\begin{array}{c}0.39(0.06- \\
0.52) \\
\end{array}$ & 0.102 & $\begin{array}{c}0.10(0.00- \\
0.60)\end{array}$ & $\begin{array}{c}0.50(0.20- \\
0.56)\end{array}$ & 0.265 \\
\hline TMSC & $1.3(0.03-16.5)$ & $10.6(0.7-21.6)$ & 0.139 & $0.3(0-9)$ & $7.7(0.1-25)$ & 0.049 \\
\hline \multicolumn{7}{|l|}{ TMSC category } \\
\hline$<5$ & $7(58.3 \%)$ & $4(33.3 \%)$ & & $13(68.4 \%)$ & $5(26.3 \%)$ & \\
\hline $5-9$ & $1(8.3 \%)$ & 0 & & $2(10.5 \%)$ & $5(26.3 \%)$ & \\
\hline$>9$ & $4(33.3 \%)$ & $8(66.7 \%)$ & 0.059 & $4(21.1 \%)$ & $9(47.4)$ & 0.008 \\
\hline
\end{tabular}

Median (interquartile range 25-75). Wilcoxon rank test was used to analyze the change in variables over time. Bolded values=statistically significant. 17-OHP: 17-hydroxyprogestrone; FSH: follicle-stimulating hormone; LH: luteinizing hormone; SA: semen analysis; TMSC: total motile sperm count. 